\title{
A Novel Reliability Technique for Implementation of Performance-Based Seismic Design of Structures
}

\author{
J. Ramon Gaxiola-Camacho ${ }^{1}$, Hamoon Azizsoltani ${ }^{2}$, Francisco J. Villegas-Mercado ${ }^{3}$, and \\ Achintya Haldar ${ }^{4}$ \\ ${ }^{1}$ Department of Civil Engineering and Engineering Mechanics, University of Arizona, P.O. Box \\ 210072, Tucson, AZ 85721, USA; PH +1 (520) 668-0104; FAX: (520) 621-2550; \\ Email: jrgaxiola@email.arizona.edu \\ ${ }^{2}$ Department of Civil Engineering and Engineering Mechanics, University of Arizona, P.O. Box \\ 210072, Tucson, AZ 85721, USA; PH +1 (520) 447-9612; FAX: (520) 621-2550; \\ Email: azizsoltani@email.arizona.edu \\ ${ }^{3}$ Department of Civil Engineering and Engineering Mechanics, University of Arizona, P.O. Box \\ 210072, Tucson, AZ 85721, USA; PH +1 (520) 912-9295; FAX: (520) 621-2550; \\ Email: fcovillegas@email.arizona.edu \\ ${ }^{4}$ Department of Civil Engineering and Engineering Mechanics, University of Arizona, P.O. Box \\ 210072, Tucson, AZ 85721, USA; PH +1 (520) 621-2142; FAX: (520) 621-2550; \\ Email: haldar@email.arizona.edu
}

\begin{abstract}
A unified Performance-Based Seismic Design (PBSD) procedure is proposed and successfully implemented. It provides an alternative to the currently used life safety design requirement. To successfully develop the concept, structures are represented by finite elements and excited by the seismic loading in time domain. A novel reliability evaluation procedure is proposed for such representation. An improved response surface based procedure is proposed by combining it with the First-Order Reliability Method (FORM) and the appropriate response surfaces are constructed by combining the saturated design and the central composite design sampling schemes. Performances are defined in terms of Collapse Prevention (CP), Life Safety (LS), and Immediate Occupancy (IO), as commonly used in the profession. The corresponding risks are evaluated by exciting a 9-story steel frame designed by experts satisfying all postNorthridge seismic design requirements. It was excited by 20 earthquake time histories for each
\end{abstract}


performance level and the corresponding probabilities of failure were estimated. It took around 300 deterministic evaluations. The accuracy of the method was established using 600,000 cycles of Monte Carlo simulations. The probabilities of failure estimated using the proposed algorithm are very similar to that of simulations indicating that it is accurate. The probability of failure for two serviceability limit states (overall and inter-story drifts) are very similar, indicating that the procedure will satisfy the basic intent of PBSD. They are also similar to the values used in developing the Load and Resistance Factor Design (LRFD) guidelines used in many current design codes. Designing a structure using multiple time histories, as suggested in recent design guidelines, is a step in the right direction. From the results and the observations made in this

study, the authors believe that they proposed a robust, efficient, and accurate unified PBSD procedure and documented its implementation potential.

Keywords: Performance-based seismic design; structural reliability; seismic risk; finite element method; response surface method; serviceability performance functions; first-order reliability method; Monte Carlo Simulation.

\section{Introduction}

Enormous amount of property damages caused by the Northridge Earthquake of 1994 prompted the profession to find an alternative to the currently used design criteria of life safety. Although the life safety was not severely compromised during the earthquake, the structural damage was enormous. Several beam-to-column connections in steel frames fractured in a brittle manner making the buildings unusable following the earthquake. Similar damages caused by previous earthquakes indicate rooms for improvements in the current prescriptive design guidelines based on the safety factor concept as used in the Allowable Stress Design (ASD) or in the Load and Resistance Factor Design (LRFD) provisions to protect life. To address the 
situation, under the sponsorship of the Federal Emergency Management Agency (FEMA), a major study by SAC [a joint venture of the Structural Engineers Association of California (SEAOC), Applied Technology Council (ATC), and California Universities for Research in Earthquake Engineering (CUREE)] was initiated in the late nineties. One of the main objectives of this study was to develop recommendations for more robust design and construction of steel structures and to propose alternative design criteria to avoid adverse economic consequences. The major findings were published in a series of reports (FEMA-350, 351, 352, 353, 355C, and 355F) [1-6].

One of the major outcomes of the SAC study was the introduction of a new design concept commonly known as the Performance-Based Seismic Design (PBSD), an alternative to the life safety design concept currently practiced. PBSD is essentially a more advanced riskbased design procedure currently used in Load and Resistance Factor Design (LRFD) [7]. The dynamic responses of a structure containing many uncertainty-filled load and resistance-related design parameters are also extremely difficult to predict. At present, the required time history of the seismic loading at a given site cannot be predicted with any confidence. The authors believe that numerous sources of uncertainty cannot be completely eliminated in any realistic seismic design and thus the absolute safety of a structure cannot be assured. The SAC study made similar conclusions and advocated that the associated risk needs to be managed appropriately. To achieve this intent, the risk of real structures to satisfy specific performance requirements need to be estimated by modeling them as appropriately as possible, applying loads the best way possible, and exciting them by seismic loading in time domain. As expected, the PBSD concept is certainly a little advanced. 
To achieve the basic objectives, SAC proposed to correlate different performance levels with the corresponding risks and let the designers and/or owners decide the level of underlying risk they are willing to accept. FEMA 350 [1] defined a performance level as: "the intended postearthquake condition of a building; a well-defined point on a scale measuring how much loss is caused by earthquake damage”. To appropriately implement the PBSD concept, it is essential that the underlying risk or probability of failure of not satisfying a prescribed performance must be explicitly quantified. Obviously, just before failure, a structure is expected to develop several sources of nonlinearities. Thus, for the successful implementation of PBSD, it will be necessary to estimate the corresponding risk by applying the seismic loading in time domain in the presence of multiple sources of nonlinearity and uncertainty. Unfortunately, SAC did not recommend any specific procedure for the risk estimation and the authors believe that no such procedure is currently available.

PBSD involves a set of procedures by which a structural system is designed in a controlled manner. The concept can be implemented by following five sequential steps: (1) select performance objectives, (2) develop preliminary design, (3) assess performance capability, (4) check performance capability with allowable values, in terms of the associated risks, and (5) if risks are not acceptable, revise the initial design. The available literature on PBSD is very limited, FEMA 355F [6] suggested that PBSD guidelines can be developed by incorporating the following six items: (1) to account for uncertainty in performance associated with unanticipated events, (2) to set realistic expectations for performance, (3) to assess performance variables in similar buildings located nearby, (4) to develop a reliability framework, (5) to set representative performance levels for various seismic hazards, and (6) to quantify local and global structural behaviors leading to collapse. The authors believe that a new reliability analysis technique is 
required to incorporate the above items. And only then the appropriate PBSD guidelines can be developed and implemented.

Limited number of studies addressing different aspects of PBSD are reported in the literature [8-11]. However, the authors are not aware of any comprehensive study addressing all the above-mentioned 6 items. This study is expected to fill such knowledge gap. Even though the reliability approach presented in this paper is little advanced, if implemented properly, it will produce more economical and seismic-damage tolerant structures by identifying the most damage-prone structural elements and by satisfying all major failure modes or performance requirements satisfying similar pre-assigned risk levels. The authors believe that other similar studies will help to develop the appropriate design guidelines to be used by engineers in the near future.

\section{Challenges in PBSD}

Some of the important challenges in implementing the PBSD concept discussed above need further elaboration. The selection of performance levels and the appropriate mathematical models to represent such behavior could be very challenging. The structure is expected to develop various sources of nonlinearities following the load path to failure and the mathematical model to capture such behavior can be very demanding. To study such nonlinear behavior realistically, the structure is generally represented by Finite Elements (FEs). Considering accuracy and efficiency, representing real large complicated structural systems by FEs could be very complicated and challenging. To study the dynamic response behavior caused by the seismic loading, several methods with various degrees of sophistication are suggested in the current design guidelines $[12,13]$. They include pseudo-static, modal, and time domain 
application of the excitation. The most sophisticated analysis requires that a structure to be represented by nonlinear FEs and the dynamic seismic loading must be applied in time domain.

Since SAC did not recommend any specific risk evaluation procedure, the authors believe that the unavailability of such procedure is a major knowledge gap in realistically implementing the PBSD concept explicitly considering all major sources of nonlinearity and uncertainty. Risk is always estimated with respect to a limit state or performance function. When the Limit Performance Function (LPF) is explicit in nature, i.e., it can be expressed in terms of all Random Variables (RVs) present in the formulation and the performance requirements, the First-Order and/or Second-Order Reliability Methods (FORM/SORM) [14] can be used to extract the corresponding risk, since the derivatives of the LPF with respect to the RVs will be readily available. However, for the implementation of the PBSD concept in the presence of nonlinearity and the excitation in time domain, LPFs are expected to be implicit in nature. A considerable amount of expertize is required to extract reliability information using FORM/SORM for implicit LPFs, as reported by Haldar and Mahadevan [14]. As an alternative, the basic Monte Carlo Simulation (MCS) can also be used to estimate the reliability [15]. Unfortunately, the use of basic MCS for the reliability analysis of a real structure excited by the seismic loading applied in time domain can be impractical since one deterministic nonlinear FE-based analysis will require several hours of computing time.

Based on the above discussions, two major objectives of this paper are: (1) to propose a novel reliability analysis concept to estimate risk of a nonlinear structure represented by FEs and excited by the seismic loading applied in time domain, and (2) to showcase the implementation of PBSD to satisfy the intents of SAC.

\section{A Unified PBSD Procedure}


Some of the most basic requirements of PBSD are the deterministic evaluation of required performances as accurately as possible, the incorporation of major sources of nonlinearities in the deterministic formulation, and then estimate the risk satisfying the appropriate performance requirements. These requirements are discussed in the following sections.

\subsection{Finite Element Representation of Structures}

In the most sophisticated deterministic response evaluations, structures are generally represented by FEs. In this representation, the major sources of nonlinearities can be incorporated as the structure passes through several phases before reaching the failure state. As mentioned earlier, the time domain nonlinear response analysis required to implement PBSD can be very challenging. To overcome this issue, the authors decided to use the assumed stress-based FE method in developing the deterministic FE code using concentrated plasticity model to capture material nonlinearity, specifically applicable for steel frame structures $[16,17]$. In this representation, fewer elements are required to represent the large deformed configuration and the tangent stiffness matrix can be expressed in an explicit form without integration at the every time step of the time domain analysis. The authors and their team members helped to develop and document the accuracy, efficiency, and capabilities of the software [18-22]. They developed a sophisticated computer program to implement the concept. For the ease of discussion, the essential features of the approach are briefly discussed below.

Without losing any generality, the nonlinear dynamic equilibrium equation of motion for large structural systems can be expressed in the matrix form at time $t+\Delta t$ as:

$$
\mathbf{M}^{t+\Delta t} \ddot{\mathbf{D}}^{(n)}+{ }^{t} \mathbf{C}^{t+\Delta t} \dot{\mathbf{D}}^{(n)}+{ }^{t} \mathbf{K}^{(n)}{ }^{t+\Delta t} \Delta \mathbf{D}^{(n)}={ }^{t+\Delta t} \mathbf{F}^{(n)}-{ }^{t+\Delta t} \mathbf{R}^{(n-1)}-\mathbf{M}^{t+\Delta t} \ddot{\mathbf{D}}_{g}^{(n)}
$$


where $\mathbf{M}$ is the mass matrix, ${ }^{t} \mathbf{C}$ is the viscous damping coefficient matrix at time $t,{ }^{t} \mathbf{K}^{(n)}$ is the global stiffness matrix of the $n^{\text {th }}$ iteration at time $t,{ }^{t+\Delta t} \Delta \mathbf{D}^{(n)}$ is the incremental displacement vector of the $n^{\text {th }}$ iteration at time $t+\Delta t,{ }^{t+\Delta t} \mathbf{F}^{(n)}$ is the external load vector of the $n^{\text {th }}$ iteration at time $t+\Delta t,{ }^{t+\Delta t} \mathbf{R}^{(n-1)}$ is the internal force vector of the $(n-1)^{\text {th }}$ iteration at time $t+\Delta t$, and ${ }^{t+\Delta t} \ddot{\mathbf{D}}_{g}^{(n)}$ is the seismic ground acceleration vector of the $n^{\text {th }}$ iteration at time $t+\Delta t$.

The amount of damping energy to be generated will depend mainly on two conditions: (1) the hysteretic behavior if the material yields, and (2) the non-yielding and yielding states of the structural elements. In structural engineering, the effect of non-yielding energy dissipation is commonly represented by viscous damping varying between 0.1 and 7 percent of the critical damping [23]. Since the mass and stiffness matrixes are available from the FE formulation, Rayleigh-type damping is utilized in this study to represent damping. It can be expressed in matrix form as:

${ }^{t} \mathbf{C}=\alpha \mathbf{M}+\gamma{ }^{t} \mathbf{K}$

where $\alpha$ and $\gamma$ are proportional constants which can be evaluated from the natural frequencies of the structure [24], and ${ }^{t} \mathbf{K}$ is the tangent stiffness matrix.

The step-by-step direct integration procedure using the Newmark method [25], with parameters $\eta=1 / 2$ and $\beta_{N}=1 / 4$, is utilized to solve Eq. (1). The iterative scheme can be represented as:

${ }^{t} \mathbf{K}_{D}{ }^{t+\Delta t} \Delta \mathbf{D}^{(n)}={ }^{t+\Delta t} \mathbf{F}_{D}^{(n)}-{ }^{t+\Delta t} \mathbf{R}^{(n-1)}$

where

${ }^{t+} \Delta t \mathbf{F}_{D}^{(n)}={ }^{t+\Delta t} \mathbf{F}_{D}^{(n-1)}+{ }^{t+\Delta t} \Delta \mathbf{F}_{D}^{(n)}$

and ${ }^{t} \mathbf{K}_{D}$ represents the dynamic tangent stiffness matrix which can be expressed as: 
${ }^{t} \mathbf{K}_{D}=f_{1} \mathbf{M}+f_{2}{ }^{t} \mathbf{K}$

In Eq. (4), ${ }^{t+\Delta t} \mathbf{F}_{D}^{(n-1)}$ and ${ }^{t+\Delta t} \Delta \mathbf{F}_{D}^{(n)}$ are the modified external force vector and its incremental vector, respectively. The modified external force vector can be represented as:

${ }^{t+} \Delta t \mathbf{F}_{D}^{(n-1)}={ }^{t+\Delta t} \mathbf{F}^{(n-1)}+{ }^{t+\Delta t} \mathbf{P}^{(n-1)}-\mathbf{M}^{t+\Delta t} \ddot{\mathbf{D}}_{g}^{(n-1)}$

${ }^{t+\Delta t} \mathbf{R}^{(n-1)}$ in Eq. (3) is the internal force vector of the system. The term ${ }^{t+\Delta t} \mathbf{P}^{(n-1)}$ in Eq. (6) is the modified force vector contributed by the displacement, velocity, and acceleration at time $t$; and the displacement at time $t+\Delta t$. It can be expressed as:

$$
\begin{aligned}
& { }^{t+\Delta t} \mathbf{P}^{(n-1)}=\mathbf{M}\left[f_{1}{ }^{t} \mathbf{D}+f_{3}{ }^{t} \dot{\mathbf{D}}+f_{4}{ }^{t} \ddot{\mathbf{D}}-f_{1}{ }^{t+\Delta t} \mathbf{D}^{(n-1)}\right]+{ }^{t} \mathbf{K}\left[f_{5}{ }^{t} \mathbf{D}+f_{6}{ }^{t} \dot{\mathbf{D}}+f_{7}{ }^{t} \ddot{\mathbf{D}}-\right. \\
& \left.f_{5}{ }^{t+\Delta t} \mathbf{D}^{(n-1)}\right]
\end{aligned}
$$

The incremental external force term ${ }^{t+\Delta t} \Delta \mathbf{F}_{D}^{(n)}$ in Eq. (4) is represented as:

$$
{ }^{t+\Delta t} \Delta \mathbf{F}_{D}^{(n)}={ }^{t+\Delta t} \Delta \mathbf{F}^{(n)}-\mathbf{M}^{t+\Delta t} \Delta \ddot{\mathbf{D}}_{g}^{(n)}
$$

The coefficients $f_{i}$ are constants which can be evaluated in terms of $\alpha, \gamma, \eta, \beta_{N}$, and $\Delta t$ as [26]:

$f_{1}=\frac{1}{\beta_{N} \Delta t^{2}}+\frac{\eta \alpha}{\beta_{N} \Delta t}, \quad f_{2}=\frac{\eta \gamma}{\beta_{N} \Delta t}+1, \quad f_{3}=\frac{1}{\beta_{N} \Delta t}+\frac{\eta \alpha}{\beta_{N}}-\alpha$,

$f_{4}=\left(\frac{1}{2 \beta_{N}}-1\right)+\eta \alpha\left(\frac{1}{2 \beta_{N}}-\frac{1}{\eta}\right) \Delta t, \quad f_{5}=\frac{\eta \alpha}{\beta_{N} \Delta t}, \quad f_{6}=\frac{\eta \gamma}{\beta_{N}}-\gamma$,

$f_{7}=\left(\frac{\eta \gamma}{2 \beta_{N}}-\gamma\right) \Delta t$

Equation (3) is solved using the modified Newton-Raphson method with arc-length control [27]. Following the above procedure, the deterministic responses in terms of displacements and forces in the structural members are estimated to implement PBSD.

\subsection{A Novel Reliability Analysis Procedure}


With the availability of the deterministic time domain nonlinear responses of structures available using the FE representation, it is now necessary to incorporate the information on uncertainties in the formulation. As mentioned earlier, for PBSD with implicit LPFs, the use of FORM/SORM can be very tedious. The authors also eliminated the basic MCS as an option because of its inefficiencies. The other alternative will be to approximately describe an implicit LPF using the Response Surface Method (RSM) [28, 29]. And then FORM can be used to extract the reliability information. To generate a Response Surface (RS), few deterministic nonlinear FE-based time domain response analyses need to be carried out around a center point following a specified sampling scheme, and a curve needs to be fitted to the generated response data. The authors believe that the risk can be estimated using few hundreds instead of several thousands or millions of deterministic evaluations using this approach filling a fundamental knowledge gap for the implementation of PBSD. However, the basic RSM concept currently utilized in the profession cannot be used for the structural reliability estimation. It has three major deficiencies: (1) it cannot incorporate the distributional information of RVs even when it is widely available, (2) if the responses are not evaluated in the failure region, which is expected to be unknown for large structural systems, the estimated risk may not be acceptable, and (3) the number of experimental sampling points necessary to generate a RS is an open question; the optimum number must be decided in an objective way. Since the distributional information on RVs and the coordinates of the Most Probable Failure Point (MPFP) or the failure region are iteratively estimated using FORM, the authors decided to integrate RSM and FORM. With this integration, the first two deficiencies of basic RSM can be removed very effectively. The authors decided to address the third deficiency by introducing an improved scheme for the selection of sampling points, as will be discussed in more detail later. To differentiate between a RS generated without 
or with improvements, a RS generated with the above integrated approach will be denoted hereafter as the improved or integrated RS or simply IRS.

\subsubsection{Generation of the IRS for Structural Reliability Evaluation}

The basic concept discussed in the previous section can be implemented by addressing the following four major issues: (1) the integration of RSM with FORM, (2) the selection of the mathematical form of the IRS, (3) the selection of center points and experimental sampling schemes, and (4) an improved sampling scheme to generate the appropriate response information to fit an IRS. All four issues are discussed next.

\subsubsection{Integration of RSM with FORM}

To generate a RS following the basic RSM concept, the center point, the sampling points, and the sampling region are selected as:

$X_{i}=X_{i}^{C}+h x_{i} \sigma_{X_{i}} \quad$ where $i=1,2, \ldots, k$

where $X_{i}$ is the region or bound of the $i^{\text {th }} \mathrm{RV}, X_{i}^{C}$ and $\sigma_{X_{i}}$ are the coordinate of the center point and the standard deviation of the $i^{\text {th }} \mathrm{RV}$, respectively, $h$ is an arbitrary factor controlling the experimental sampling region, $x_{i}$ is the coded variable which has values of $0, \pm 1$ or $\pm \sqrt[4]{2^{k}}$, depending on the coordinate of the experimental sampling points with respect to the center points, and $k$ is the number RVs. Clearly, the formulation represented by Eq. (10) fails to incorporate the distribution information of RVs even when it is available and the selection of the center point is arbitrary in nature.

In order to include distribution information of RVs and to generate a RS in the failure region, the authors propose to integrate RSM and FORM in the unified PBSD procedure. The iterative process of FORM will capture the underlying distribution information of RVs and will locate the coordinates of the failure region iteratively. In the first iteration, the coordinates of the 
center point will be assumed to be the mean values of all RVs, as is generally assumed to implement FORM. In the context of FORM, the reliability is estimated in the normal variable space. For the successful integration, all non-normal RVs need to be transformed to equivalent normal variables during the first iteration of FORM. The equivalent normal mean $\left(\mu_{X_{i}}^{N}\right)$ and standard deviation $\left(\sigma_{X_{i}}^{N}\right)$ can be calculated by equating the Probability Density Functions (PDFs) and Cumulative Distribution Functions (CDFs) of the original non-normal variables to those of the equivalent normal variables [14] as:

$\mu_{X_{i}}^{N}=x_{i}^{*}-\Phi^{-1}\left[F_{X_{i}}\left(x_{i}^{*}\right)\right] \sigma_{X_{i}}^{N}$

and

$\sigma_{X_{i}}^{N}=\frac{\emptyset\left\{\Phi^{-1}\left[F_{X_{i}}\left(x_{i}^{*}\right)\right]\right\}}{f_{X_{i}}\left(x_{i}^{*}\right)}$

where $x_{i}^{*}$ is the checking point, $\Phi()$ and $\emptyset()$ are the CDF and PDF of the standard normal variable, respectively, and $F_{X_{i}}\left(x_{i}^{*}\right)$ and $f_{X_{i}}\left(x_{i}^{*}\right)$ represent the CDF and PDF of the original nonnormal variables at the checking point $x_{i}^{*}$, respectively. Thus, the iteration process of FORM will be initiated by replacing $X_{i}$ and $\sigma_{X_{i}}$ in Eq. (10) by $\mu_{X_{i}}^{N}$ and $\sigma_{X_{i}}^{N}$, respectively. The next step will be the selection of the mathematical form of an IRS, as discussed next.

\subsubsection{Mathematical form of an IRS}

The selection of mathematical form of an IRS is the next challenge. Obviously, in the context of PBSD, it is not expected to be linear. It is reported in the literature that the selection of more than second-order polynomial for an IRS can be very problematic [28]. The authors decided to represent an IRS using a second-order polynomial without or with cross terms. The polynomials can be expressed as: 
$\hat{g}(\boldsymbol{X})=b_{0}+\sum_{i=1}^{k} b_{i} X_{i}+\sum_{i=1}^{k} b_{i i} X_{i}^{2}$

$\hat{g}(\boldsymbol{X})=b_{0}+\sum_{i=1}^{k} b_{i} X_{i}+\sum_{i=1}^{k} b_{i i} X_{i}^{2}+\sum_{i=1}^{k-1} \sum_{j>1}^{k} b_{i j} X_{i} X_{j}$

where $X_{i}(i=1,2, \ldots, k)$ is the $i^{\text {th }} \mathrm{RV}, k$ is the total number of RVs involved in the problem, $b_{0}, b_{i}$, $b_{i i}$ and $b_{i j}$ are the unknown coefficients to be determined, and $\hat{g}(\boldsymbol{X})$ is the approximate representation of the original unknown LPF $g(\boldsymbol{X})$. The number of coefficients required to define Eqs. (13) and (14) are $2 k+1$, and $(k+1)(k+2) / 2$, respectively. When $k=6$, the number of unknown coefficients required to define Eqs. (13) and (14) will be 13 and 28, respectively. However, when $k$ is large, say 60, as expected for a realistic structure, the corresponding numbers will be 121 and 1891, respectively, indicating a significant increase in the computational time if Eq. (14) is used. Additionally, the selection of experimental sampling points to generate response information plays an important role in the efficiency of the procedure.

\subsubsection{Selection of Center Points and Experimental Sampling Schemes}

In the context of IRS, the coordinates of the initial center point will be mean values of RVs, as in FORM, and the location of the center point will be updated as the iteration continues. To generate response information in developing a required IRS, several deterministic nonlinear time domain FE analyses need to be conducted around a center point at specific points commonly known as "experimental sampling points" following a sampling scheme. The sampling scheme is also expected to influence the accuracy and efficiency of the algorithm. Two commonly used sampling schemes reported in the literature are Saturated Design (SD) and 
Central Composite Design (CCD) [28]. SD is less accurate, but more efficient since it requires only as many deterministic FE analyses as the total number of unknown coefficients necessary to define the polynomial by solving a set of linear equations. Also, a second-order polynomial without and with cross terms can be used to generate an IRS using the SD scheme, requiring $2 k+1$ and $(k+1)(k+2) / 2$ number of deterministic FE analyses, respectively. On the other hand, CCD is more accurate but less efficient since it can generate only a second-order polynomial with cross terms and a regression analysis is needed to obtain the unknown coefficients. CCD consists of one center point, two axial points located on the axis of each RV at a distance equal to $\sqrt[4]{2^{k}}$ measured from the center point, and $2^{k}$ factorial points. Hence, the total number of deterministic FE analyses in CCD is equal to $2^{k}+2 k+1$. More comprehensive discussions on SD and CCD can be found in the literature [28, 30, 31].

In general, to implement PBSD for large realistic structural systems, the total number of RVs is expected to be large. For the sake of discussion, suppose $k=40$. The Total Number of Sampling Points (TNSPs) or deterministic nonlinear time domain FE analyses required to define Eq. (13) using the SD scheme will be $2 * 40+1=81$ and to define Eq. (14) will be ( $40+$ 1) $(40+2) / 2=861$. If CCD is used, it will require $2^{40}+2 * 40+1=1,099,511,627,857$ TNSPs. Obviously, CCD cannot be used for large structural systems. Considering both the efficiency and accuracy, the authors propose a two-stage approach. In the first stage, they plan to reduce the total number of RVs in the formulation. In the second stage, they plan to combine the desirable features of SD and $\mathrm{CCD}$, as discussed next.

\subsubsection{Improved Sampling Scheme}

It is obvious that when $k$ is large, the CCD scheme cannot be implemented. It is known to the profession that the propagation of uncertainties from the parameter to system level is very 
non-uniform. A measure called the sensitivity index can be used to quantify the influence of each RV [14]. The sensitivity of a variable $X$ is the directional cosines $\alpha(X)$ of the unit normal variable at the checking or design point. The gradient vector of the LPF in the standard normal variable space can be used for this purpose and will be available from the FORM analysis. RVs with low sensitivity indexes at the end of the first iteration can be treated as deterministic at their mean values in the subsequent iterations. The authors observed that the reduction of the total number of RVs significantly improves efficiency without compromising accuracy. The reduced number of RVs will be denoted as $k_{r}$ in this paper. Suppose, that out of a total of $40 \mathrm{RVs}$, only 7 are sensitive, the required TNSPs will be $2^{7}+2 * 7+1=143$, a significant reduction. This will be demonstrated with the help of examples later.

In proposing an Improved Sampling Scheme (ISS), in the second stage, the authors propose to use SD without cross terms (Eq. 13) in the intermediate iterations to increase efficiency and CCD with cross terms (Eq. 14) in the final iteration to increase accuracy, as shown in Fig. 1. For example, if $k=40$ and $k_{r}=7$, the TNSPs required to implement the proposed ISS considering three iterations will be $(2 * 40+1)+(2 * 7+1)+\left(2^{7}+2 * 7+\right.$ 1) $=239$. Hence, the ISS captures the efficiency of SD and the accuracy of CCD in one single scheme in the proposed reliability evaluation procedure.

\subsubsection{Performance Levels}

The selection of performance levels and the corresponding risks according to specific LPFs are the essence of PBSD. In constructing a specific LPF, the information on generated IRS as discussed in Section 3.2.1 needs to be integrated with the performance level. FEMA 350 [1] defined three performance levels; they range from immediate occupancy to collapse prevention. The Immediate Occupancy (IO) represents the performance of a building that has sustained 
minimal or no damage to its structural elements and only minor damage to its nonstructural components. The Life Safety (LS) level represents a structure with extensive damage; the risk to life is low, but repairs may be required before re-occupancy. The Collapse Prevention (CP) level is represented by a building that has suffered extensive structural damage; total collapse is avoided, but structural repairs are uneconomical. PBSD criteria are usually established on the basis of multiple target performance levels. FEMA 350 [1] proposed the performance levels for $\mathrm{CP}, \mathrm{LS}$, and IO in terms of earthquake return period, probability of exceedence, and allowable drifts. The information is summarized in Table 1 . The allowable drift is a function of $H$; it represents the total height of the building for the overall allowable drift at the top of the roof. For the allowable inter-story drift, $H$ represents the story height. The information provided in Table 1 is essentially for serviceability LPFs.

At present, a structure is analyzed and designed for strength first. It is then checked for serviceability-related issues like overall lateral and inter-story stiffness to assure that it does not develop excessive lateral and inter-story deformations. From the past studies $[32,33]$, the research team members of the authors observed that the structural members are generally designed conservatively but the structure may not be able to satisfy the serviceability limit states, particularly when lateral load caused by the seismic excitation controls the design. Most of these structures fail by developing excessive lateral or inter-story deformation. The authors believe that the SAC project also made similar observations and suggested PBSD design criteria for serviceability-related performance functions only. This prompted the authors to study only the serviceability-related issues in this paper.

\subsubsection{Serviceability Performance Evaluation}


The most commonly used serviceability LPFs related to the overall top roof displacement and inter-story drift are generally expressed as:

$g(\mathbf{X})=\delta_{\text {allow }}-y_{\text {max }}(\mathbf{X})=\delta_{\text {allow }}-\hat{g}(\mathbf{X})$

where $\delta_{\text {allow }}$ can be selected based on the performance requirements, as summarized in Table 1 and $y_{\max }(\mathbf{X})$ is the appropriate IRS which can be represented as $\hat{g}(\mathbf{X})$, where $\hat{g}(\mathbf{X})$ is the explicit polynomial function constructed using IRS, as discussed in Section 3.2.1.

\subsubsection{Structural Reliability Estimation}

At this stage, explicit expressions for appropriate LPFs are available and FORM will be used to extract the reliability information. A required LPF will be generated using the performance requirement and the corresponding IRS. To construct an IRS, the necessary response information will be generated at the sampling points, by calculating the maximum responses caused by an earthquake time history applied in time domain using a nonlinear FE algorithm. As in FORM, the first iteration will be initiated at the mean values of all RVs in the normal variable space. The LPF of interest will be generated using a second-order polynomial without cross terms (Eq. 13) and SD sampling schemes. In the process of implementing FORM, the direction cosines $\left(\alpha_{i}\right)$ or the sensitivity index of all the RVs will be generated. As discussed earlier, RVs with relatively smaller sensitivity indexes will be considered deterministic at their mean values and a new LPF will be generated. With the reduced number of RVs and modified IRS, the LPF will be reconstructed. Following the FORM strategy, the iteration will continue until the direction cosines of all remaining RVs converged to a pre-determine tolerance level. For this study, a tolerance level of 0.005 is used. It may take few iterations $[14,15]$. Then, the first estimate of the reliability index $\beta$ will be made using the standard FORM procedure. The coordinates of the new checking point $\left(x_{i}^{*}\right)$ or center point will be recalculated as: 
$x_{i}^{*}=\mu_{X_{i}}^{N}-\alpha_{i} \beta \sigma_{X_{i}}^{N}$

The overall updating will continue until $\beta$ converges satisfying a pre-determine tolerance level. In this study, the tolerance level for $\beta$ is considered to be 0.001 . In the context of ISS, in the last iteration, the CCD sampling scheme and a second-order polynomial with cross terms (Eq. 14) will be used to generate an IRS and the corresponding LPF. In most cases, it may take 3 to 5 iterations to complete the iterative process in determining the final $\beta$ value. Once $\beta$ converges, the coordinates of the last checking point $\boldsymbol{x}^{*}$ representing the MPFP can be calculated as:

$\beta=\sqrt{\left(\boldsymbol{x}^{*}\right)^{t}\left(\boldsymbol{x}^{*}\right)}$

The corresponding probability of failure $\left(p_{f}\right)$ can be estimated as:

$p_{f}=\Phi(-\beta)=1.0-\Phi(\beta)$

A flowchart of the unified PBSD procedure is shown in Fig. 2.

\section{Uncertainty in Load and Resistance-Related RVs}

The success of the novel reliability technique for the implementation of PBSD will depend on how the uncertainty associated with the load and resistance-related RVs is incorporated in the formulation. In implementing PBSD, the following three issues need to be specifically addressed: (1) how to quantify the uncertainty in the seismic acceleration time histories during the life time of the structure, (2) how to quantify uncertainty in the gravity loads, and (3) how to quantify uncertainty in the resistance related parameters.

\subsection{Uncertainty in the seismic acceleration time histories}

The incorporation of uncertainties in the time domain seismic analysis is still evolving. Conceptually, structures need to be excited by the two horizontal and one vertical acceleration time histories to produce the most critical performance of interest. The uncertainty associated 
with the intensity level and frequency contents also need to be addressed. To incorporate uncertainty in the intensity, a factor $\left(g_{e}\right)$, is considered in this study. It is considered to be a RV and represented by a Type I distribution with a coefficient of variation (COV) of 0.2. It will be discussed further in the example section.

Consideration of uncertainty in the frequency content of an earthquake time history is still under development. In recent design guidelines at least seven probable time histories expected for the location under consideration are suggested [12, 13]. In the absence of other alternatives, the authors believe that this is a step in the right direction. For PBSD with multiple performance requirements, the information on the Probability of Exceedence (PE) can be related to the performance level. During the second phase of the SAC project, Somerville et al. [34] suggested three sets of ground motion time histories corresponding to $2 \%, 10 \%$, and $50 \% \mathrm{PE}$ in 50 years for the Los Angeles (LA) area and correlated them with the performance levels of CP, LS, and IO, respectively, as summarized in Tables 1 and 2. For each performance level, 10 ground motion events with two horizontal orthogonal components providing 20 time histories were suggested. They used scale factors (SFs) to match target spectral values, on an average, for the periods of $0.3,1.0,2.0$, and 4.0 seconds for site category of $\mathrm{S}_{\mathrm{D}}$ (firm soil), suggested by the United States Geological Survey (USGS). The information is summarized in Table 2. Thus, for each performance level of CP, LS, and IO, 20 time histories are available, as summarized in Tables 3,4 , and 5 , respectively. The authors used these time histories to verify the PBSD guidelines incorporating uncertainties in the intensity and the frequency contents of earthquake time histories, satisfying the intent of FEMA 350 [1].

\subsection{Uncertainty in the Gravity Loads}


For the seismic analysis, the gravity loads are considered to be Dead Load (DL) and Live Load (LL), in most design guidelines $[12,13]$. The uncertainties associated with them are widely reported in the literature $[7,14]$ and the authors used the same information in this study also. DL and LL are represented by normal and Type I distributions with COV of 0.10 and 0.25 , respectively, as shown in Table 6.

\subsection{Uncertainty in the resistance related parameters}

The information on uncertainty associated with the resistance related parameters widely used in the profession is also used in this study [7, 14]. Young's modulus $(E)$, yield stress of columns $\left(F_{y c}\right)$ and girders $\left(F_{y g}\right)$, the cross sectional area $(A)$, and moment of inertia $(I)$ of Wsections used for structural elements are considered to be RVs with a lognormal distribution with COV of 0.06, 0.10, 0.10, 0.05, and 0.05, respectively, as shown in Table 6 .

\section{Implementation and Demonstration of the Proposed Unified PBSD Procedure}

At this stage, since all the elements of the proposed unified PBSD procedure are available, it is essential to demonstrate the implementation potential of the approach with the help of an illustrative example. As part of the SAC project, several steel buildings were designed by experts for further investigations [1-6]. Among many structural systems reported in FEMA355C [5], a 9-story building designed for LA area is studied to demonstrate the proposed procedure. The structure was designed by expert practicing engineers by satisfying all postNorthridge design criteria. The current code requirements are expected to follow the similar guidelines. The building consists of two-dimensional steel frames made with $\mathrm{W}$-sections. A typical frame with size of columns and girders and the distributed loads acting on it is shown in

Fig. 3. $\mathrm{W}_{\mathrm{D} 1}$ and $\mathrm{W}_{\mathrm{D} 2}$ represent $\mathrm{DL}$ at the roof and floor levels, respectively. $\mathrm{W}_{\mathrm{L} 1}$ and $\mathrm{W}_{\mathrm{L} 2}$ are the LL for roof and floor levels, respectively. The main intent of this example is to document that 
structures designed using PBSD will satisfy similar reliability requirements for different performance levels.

The statistical information on all RVs is summarized in Table 6. One can observe that the total number of RVs for both overall top roof and inter-story drift LPFs is 68. To reduce the total number of RVs, each LPF is considered separately and the corresponding LPF is constructed using IRS with the SD scheme and without the cross terms (Eq. 13). Then, using FORM, the direction cosines or the sensitivity indexes of RVs are estimated. For both LPFs, 7 RVs are found to be the most sensitive and are considered to be RVs in the subsequent analyses. All others are considered to be deterministic at their mean values.

The probability of failure, $p_{f}$, for serviceability conditions is evaluated using the proposed reliability analysis procedure using ISS. The serviceability LPFs are considered to be the overall drift at the top of the frame (LPF1) and the inter-story drift at the $4^{\text {th }}$ floor level (LPF2). The allowable drifts $\left(\delta_{\text {allow }}\right)$ for LPF1 are considered to be $188.1,94.05$, and $26.33 \mathrm{~cm}$ for CP, LS, and IO performance levels, respectively. The corresponding allowable drifts for LPF2 are considered to be $19.8,9.9$, and $2.7 \mathrm{~cm}$, respectively. The frame is then excited by 20 time histories for each of the CP, LS, and IO performance level. The reliability indexes $\beta$ for two LPFs are then calculated and reported in Tables 3-5. The mean reliability indexes $(\bar{\beta})$ and the corresponding probabilities of failure, $p_{f}$, are summarized in Table 7.

To establish the accuracy of the proposed algorithm, the information on the probability of failure is extracted by using the classical MCS. Obviously, it will take an enormous amount of time to estimate $p_{f}$ considering all time histories, performance levels, and LPFs. For this reason, the probabilities of failure for the two LPFs when exited by only the earthquake time history no. 
36 (Table 4) are given in this paper. The TNSPs or total number of deterministic evaluations required to generate them using the ISS and using 600,000 MCSs are summarized in Table 8.

Several important observations can be made from the results obtained from the study. The results given in Table 8 clearly indicate the probabilities of failure estimated using the proposed algorithm are very similar to that of MCS indicating that it is accurate. However, the information on $p_{f}$ is extracted using only 310 TNSPs; not 600,000 simulations of MCS. Obviously, the proposed method not only is accurate but also efficient. The $p_{f}$ for the two serviceability LPFs are very similar and of the order of $10^{-6}$. The results are very exciting for several reasons. Since the results for two LPFs are very similar, they satisfy the intent of PBSD, i.e., $p_{f}$ should be similar for different LPFs. The authors also observed that the $p_{f}$ values are similar to the values used in developing the LRFD requirements used in many currently used design guidelines. The reliability indexes versus the earthquake time histories are plotted in Figs. 4 and 5. The $\beta$ values obtained for the two components of the same earthquake are different. It clearly indicates that designing a structure for one design earthquake time history is inadequate. Designing a structure using multiple time histories, as suggested in recent design guidelines [12, 13], is a step in the right direction. The mean values of $\beta$ for CP, LS, and IO performance levels for LPF1 are 7.06, 6.96, and 6.57, respectively and the corresponding values for LPF2 are 6.22, 6.32, and 6.05. From the above results, the authors believe that the allowable values suggested in the design guidelines [1] are reasonable. The $\beta$ values fall within a range, satisfying the intent of the code. It is also interesting to note the distinct separations of performance levels of CP, LS, and IO in Figs. 4 and 5. It indicates that the SFs to match target spectral values at certain frequencies by Somerville et al. [34] are reasonable. The same procedure can be used for the 
PBSD for the time being. The authors are in the process of developing another alternative. It will be reported in the near future.

From the results and the observations made in this study, the authors believe that they proposed a robust, efficient, and accurate reliability analysis procedure for nonlinear structures represented by finite elements and excited by the seismic loading in time domain. Using the procedure, they developed a unified PBSD procedure, successfully implemented it, and demonstrated how to use it with the help of an illustrative example.

\section{Conclusions}

Issues related to developing and implementing PBSD are presented in this paper. Since a required performance level cannot be assured for a specific design, it must be assessed in terms of the associate risk or reliability. In the implementation of PBSD, the required performances need to be assessed as accurately as possible similar to the procedures followed by the deterministic community. Some of the major building blocks of the proposed procedure are: (1) structures are represented by finite elements and excited by earthquake time histories applied in time domain to produce the critical performance level of interest, (2) since the required limit or performance functions are implicit for the class of problems under consideration, they are formulated using the response surface concept but removing its three majors deficiencies, (3) the required performance information needed to explicitly generate a response surface, saturated design and central composite design sampling schemes are used and their various alternatives are proposed, (4) FORM is used to extract reliability information, and (5) several efficiency improvements schemes are proposed. It is capable of generating a response surface with hundreds of deterministic nonlinear finite element analyses. The proposed method is verified by estimating risk of a 9-story steel building designed by expert professional engineers satisfying 
the post-Northridge design requirements. It was excited by 20 earthquake time histories for each performance level of $\mathrm{CP}, \mathrm{LS}$, and IO, and the corresponding reliability indexes were estimated using the proposed method. It took around 300 deterministic evaluations using the improved sampling scheme proposed in the paper. The accuracy of the method was established using 600,000 cycles of simulations. Several important observations can be made from this study including: (1) the probabilities of failure estimated using the proposed algorithm are very similar to that of MCS indicating that it is accurate, (2) the $p_{f}$ for the two serviceability LPFs are very similar; of the order of $10^{-6}$, (3) since the results for two LPFs are very similar, they satisfy the intent of PBSD, i.e., they should be similar for different LPFs, and (4) results are also similar to

the values used in developing the LRFD guidelines used in many current design codes. The study confirms that designing structures using multiple time histories, as suggested in recent design guidelines, is a step in the right direction. The authors believe that the study documented how to develop and implement the PBSD guidelines with the help of an informative example.

\section{Acknowledgments}

This study is based on work partly supported by several agencies from the government of Mexico: Consejo Nacional de Ciencia y Tecnología (CONACYT), Universidad Autónoma de Sinaloa (UAS), and Dirección General de Relaciones Internacionales de la Secretaria de Educación Pública (DGRI-SEP). This study is also partially supported by the National Science Foundation under Grant No. CMMI-1403844. Any opinions, findings, conclusions, or recommendations expressed in this paper are those of the writers and do not necessarily reflect the views of the sponsors.

\section{References}

[1] FEMA-350. Recommended Seismic Design Criteria for New Steel Moment-Frame Buildings. Federal Emergency Management Agency (FEMA), 2000. 
[2] FEMA-351. Recommended Seismic Evaluation and Upgrade Criteria for Existing Welded Steel Moment-Frame Buildings. Federal Emergency Management Agency (FEMA), 2000.

[3] FEMA-352. Recommended Post-earthquake Evaluation and Repair Criteria for Welded Steel Moment-Frame Buildings. Venture, SAC Joint. Federal Emergency Management Agency, Washington, DC 2000.

[4] FEMA-353. Recommended Specifications and Quality Assurance Guidelines for Steel Moment-Frame Construction for Seismic Applications. Federal Emergency Management Agency (FEMA), 2000.

[5] FEMA-355C. State of the Art Report on Systems Performance of Steel Moment Frames Subject to Earthquake Ground Shaking. Venture, SAC Joint. Federal Emergency Management Agency, 2000.

[6] FEMA-355F. State of the Art Report on Performance Prediction and Evaluation of Steel Moment-Frame Buildings. Venture, SAC Joint. Federal Emergency Management Agency, 2000.

[7] Ellingwood B. Development of a probability based load criterion for American National Standard A58: Building code requirements for minimum design loads in buildings and other structures. US Department of Commerce, National Bureau of Standards, 1980.

[8] Gu J. Using Parallel Computer Systems to Examine Seismic Reliability of Structures. J Steel Struct Constr 2015;1:12-9.

[9] Kazantzi A, Vamvatsikos D, Lignos D. Seismic performance of a steel moment-resisting frame subject to strength and ductility uncertainty. Eng Struct 2014;78:69-77.

[10] FEMA P-58-1. Seismic Performance Assessment of Buildings. Federal Emergency Management Agency (FEMA), 2012.

[11] FEMA-445, Next-generation performance-based seismic design guidelines-program plan for new and existing buildings 2006.

[12] ASCE/SEI 7-10. Minimum Design Loads for Buildings and Other Structures. American Society of Civil Engineers. Reston, Virginia 20191: ASCE, 2010.

[13] IBC. International Code Council. International Building Code. International Code Council. Washington DC, United States 2012.

[14] Haldar A, Mahadevan S. Probability, reliability, and statistical methods in engineering design. John Wiley \& Sons, Incorporated, 2000.

[15] Haldar A, Mahadevan S. Reliability assessment using stochastic finite element analysis. John Wiley \& Sons, 2000. 
[16] Kondoh K, Atluri S. Large-deformation, elasto-plastic analysis of frames under nonconservative loading, using explicitly derived tangent stiffnesses based on assumed stresses. Comput Mech 1987;2:1-25.

[17] Shi G, Atluri S. Elasto-plastic large deformation analysis of space-frames: A plastic-hinge and stress-based explicit derivation of tangent stiffnesses. Int J Numer Methods Eng 1988;26:589-615.

[18] Gao L, Haldar A. Nonlinear Seismic Analysis of Space Structures with Partially Restrained Cnnections. Computer-Aided Civil and Infrastructure Engineering 1995;10:27-37.

[19] Reyes-Salazar A, Haldar A. Nonlinear seismic response of steel structures with semi-rigid and composite connections. Journal of Constructional steel research 1999;51:37-59.

[20] Huh J, Haldar A. Stochastic finite-element-based seismic risk of nonlinear structures. J Struct Eng 2001;127:323-9.

[21] Lee SY, Haldar A. Reliability of frame and shear wall structural systems. II: Dynamic loading. J Struct Eng 2003;129:233-40.

[22] Haldar A, Huh J, Mehrabian A. Time-domain seismic reliability of nonlinear structures. Sadhana 2006;31:359-82.

[23] Léger P, Dussault S. Seismic-energy dissipation in MDOF structures. J Struct Eng 1992;118:1251-69.

[24] Clough RW, Penzien J. Dynamics of Structures: McGraw-Hill, 1993.

[25] Bathe K. Finite element procedures: Klaus-Jurgen Bathe, 2006.

[26] Haldar A, Ker-Ming N. Elasto-plastic large deformation analysis of PR steel frames for LRFD. Comput Struct 1989;31:811-23.

[27] Haldar A, Nee K. An efficient algorithm for nonlinear seismic response of multiple-support excitation 1989.

[28] Khuri AI, Cornell JA. Response surfaces: designs and analyses: CRC press, 1996.

[29] Faravelli L. Response-surface approach for reliability analysis. J Eng Mech 1989;115:276381.

[30] Box GE, Wilson K. On the experimental attainment of optimum conditions. Journal of the Royal Statistical Society.Series B (Methodological) 1951;13:1-45.

[31] Box GEP, Hunter WG, Hunter JS. Statistics for experimenters: an introduction to design, data analysis, and model building: Wiley, 1978. 
[32] Salazar AR, Haldar A. Energy dissipation at PR frames under seismic loading. J Struct Eng 2001;127:588-92.

[33] Reyes-Salazar A, Haldar A. Seismic response and energy dissipation in partially restrained and fully restrained steel frames: an analytical study. Steel and Composite Structures 2001;1:459-80.

[34] Somerville PG, Venture SJ. Development of ground motion time histories for phase 2 of the FEMA/SAC steel project: SAC Joint Venture, 1997. 
Table 1. Performance level, earthquake return period, probability of exceedence, and allowable drift relations.

\begin{tabular}{cccc}
\hline $\begin{array}{c}\text { Performance } \\
\text { Level }\end{array}$ & $\begin{array}{c}\text { Earthquake } \\
\text { Return } \\
\text { Period }\end{array}$ & $\begin{array}{c}\text { Probability of } \\
\text { Exceedence }\end{array}$ & $\begin{array}{c}\text { Allowable Drift } \\
\left(\boldsymbol{\delta}_{\text {allow }}\right)\end{array}$ \\
\hline CP & 2475 -year & $2 \%$ in 50 years & $0.050 * H$ \\
LS & 475 -year & $10 \%$ in 50 years & $0.025 * H$ \\
IO & 72 -year & $50 \%$ in 50 years & $0.007 * H$ \\
\hline
\end{tabular}

Table 2. Target response spectra values in terms of gravitational acceleration (g).

\begin{tabular}{ccccc}
\hline \multirow{2}{*}{ Probability of exceedence } & \multicolumn{4}{c}{ Period (sec.) } \\
\cline { 2 - 5 } & $\mathbf{0 . 3}$ & $\mathbf{1 . 0}$ & $\mathbf{2 . 0}$ & $\mathbf{4 . 0}$ \\
\hline 2\% in 50 years (CP) & 1.610 & 1.190 & 0.540 & 0.190 \\
10\% in 50 years (LS) & 1.070 & 0.680 & 0.330 & 0.123 \\
50\% in 50 years (IO) & 0.514 & 0.288 & 0.149 & 0.069 \\
\hline
\end{tabular}

Table 3. Set 1: 2475-year return period time histories for CP performance level.

\begin{tabular}{|c|c|c|c|c|c|c|c|c|}
\hline \multirow{2}{*}{ EQ } & \multirow{2}{*}{$\begin{array}{l}\text { Record } \\
\text { Name }\end{array}$} & \multirow{2}{*}{$\mathbf{S F}$} & \multirow{2}{*}{$\begin{array}{c}\text { PGA } \\
(\mathrm{g})\end{array}$} & \multirow{2}{*}{$\begin{array}{c}\text { Excitation } \\
\text { Time } \\
\text { (sec) }\end{array}$} & \multicolumn{2}{|c|}{ LPF1 } & \multicolumn{2}{|c|}{ LPF2 } \\
\hline & & & & & $\beta$ & TNSP & $\beta$ & TNSP \\
\hline 1 & 1995 Kobe & 1.15 & 1.282 & 25.0 & 5.24 & 295 & 4.55 & 295 \\
\hline 2 & 1995 Kobe & 1.15 & 0.920 & 25.0 & 6.39 & 295 & 5.74 & 295 \\
\hline 3 & 1989 Loma Prieta & 0.82 & 0.418 & 20.0 & 9.58 & 295 & 8.92 & 280 \\
\hline 4 & 1989 Loma Prieta & 0.82 & 0.473 & 20.0 & 6.88 & 295 & 6.58 & 295 \\
\hline 5 & 1994 Northridge & 1.29 & 0.868 & 14.0 & 6.79 & 310 & 6.44 & 280 \\
\hline 6 & 1994 Northridge & 1.29 & 0.943 & 14.0 & 5.44 & 295 & 4.59 & 295 \\
\hline 7 & 1994 Northridge & 1.61 & 0.926 & 15.0 & 7.20 & 310 & 8.60 & 310 \\
\hline 8 & 1994 Northridge & 1.61 & 1.329 & 15.0 & 5.76 & 295 & 5.06 & 295 \\
\hline 9 & 1974 Tabas & 1.08 & 0.808 & 25.0 & 10.95 & 295 & 9.91 & 295 \\
\hline 10 & 1974 Tabas & 1.08 & 0.991 & 25.0 & 8.35 & 310 & 7.62 & 295 \\
\hline 11 & Elysian Park (simulated) & 1.43 & 1.295 & 18.0 & 6.28 & 280 & 7.22 & 280 \\
\hline 12 & Elysian Park (simulated) & 1.43 & 1.186 & 18.0 & 6.13 & 295 & 4.33 & 295 \\
\hline 13 & Elysian Park (simulated) & 0.97 & 0.782 & 18.0 & 7.78 & 295 & 7.16 & 280 \\
\hline 14 & Elysian Park (simulated) & 0.97 & 0.680 & 18.0 & 6.53 & 310 & 5.99 & 310 \\
\hline 15 & Elysian Park (simulated) & 1.1 & 0.991 & 18.0 & 8.97 & 310 & 4.30 & 310 \\
\hline 16 & Elysian Park (simulated) & 1.1 & 1.100 & 18.0 & 5.02 & 310 & 4.09 & 310 \\
\hline 17 & Palos Verdes (simulated) & 0.9 & 0.711 & 25.0 & 6.89 & 310 & 6.41 & 310 \\
\hline 18 & Palos Verdes (simulated) & 0.9 & 0.776 & 25.0 & 7.34 & 295 & 4.29 & 295 \\
\hline 19 & Palos Verdes (simulated) & 0.88 & 0.500 & 25.0 & 7.59 & 295 & 6.96 & 310 \\
\hline 20 & Palos Verdes (simulated) & 0.88 & 0.625 & 25.0 & 6.16 & 310 & 5.66 & 310 \\
\hline
\end{tabular}


Table 4. Set 2: 475-year return period time histories for LS performance level.

\begin{tabular}{|c|c|c|c|c|c|c|c|c|}
\hline \multirow{2}{*}{ EQ } & \multirow{2}{*}{$\begin{array}{c}\text { Record } \\
\text { Name }\end{array}$} & \multirow{2}{*}{ SF } & \multirow{2}{*}{$\begin{array}{c}\text { PGA } \\
(\mathrm{g})\end{array}$} & \multirow{2}{*}{$\begin{array}{c}\text { Excitation } \\
\text { Time } \\
\text { (sec) }\end{array}$} & \multicolumn{2}{|c|}{ LPF1 } & \multicolumn{2}{|c|}{ LPF2 } \\
\hline & & & & & $\beta$ & TNSP & $\beta$ & TNSP \\
\hline 21 & Imperial Valley, 1940 & 2.01 & 0.461 & 25.0 & 7.11 & 295 & 6.42 & 295 \\
\hline 22 & Imperial Valley, 1940 & 2.01 & 0.675 & 25.0 & 7.67 & 310 & 7.06 & 295 \\
\hline 23 & Imperial Valley, 1979 & 1.01 & 0.393 & 15.0 & 6.98 & 295 & 6.38 & 280 \\
\hline 24 & Imperial Valley, 1979 & 1.01 & 0.488 & 15.0 & 10.51 & 310 & 9.84 & 280 \\
\hline 25 & Imperial Valley, 1979 & 0.84 & 0.301 & 15.0 & 7.94 & 295 & 7.36 & 310 \\
\hline 26 & Imperial Valley, 1979 & 0.84 & 0.234 & 15.0 & 10.94 & 310 & 10.64 & 310 \\
\hline 27 & Landers, 1992 & 3.2 & 0.421 & 30.0 & 7.67 & 310 & 7.03 & 295 \\
\hline 28 & Landers, 1992 & 3.2 & 0.425 & 30.0 & 7.46 & 295 & 6.98 & 295 \\
\hline 29 & Landers, 1992 & 2.17 & 0.519 & 30.0 & 4.44 & 310 & 4.00 & 295 \\
\hline 30 & Landers, 1992 & 2.17 & 0.360 & 30.0 & 6.14 & 310 & 5.53 & 310 \\
\hline 31 & Loma Prieta, 1989 & 1.79 & 0.665 & 16.0 & 6.97 & 310 & 6.23 & 295 \\
\hline 32 & Loma Prieta, 1989 & 1.79 & 0.969 & 16.0 & 9.55 & 295 & 8.87 & 310 \\
\hline 33 & Northridge, 1994, Newhall & 1.03 & 0.678 & 15.0 & 5.90 & 295 & 5.17 & 295 \\
\hline 34 & Northridge, 1994, Newhall & 1.03 & 0.657 & 15.0 & 5.03 & 280 & 4.13 & 280 \\
\hline 35 & Northridge, 1994, Rinaldi & 0.79 & 0.533 & 14.0 & 5.61 & 295 & 4.45 & 295 \\
\hline 36 & Northridge, 1994, Rinaldi & 0.79 & 0.579 & 14.0 & 4.34 & 310 & 3.80 & 310 \\
\hline 37 & Northridge, 1994, Sylmar & 0.99 & 0.569 & 15.0 & 7.84 & 295 & 7.39 & 310 \\
\hline 38 & Northridge, 1994, Sylmar & 0.99 & 0.817 & 15.0 & 4.97 & 295 & 3.96 & 280 \\
\hline 39 & North Palm Springs, 1986 & 2.97 & 1.018 & 16.0 & 7.57 & 310 & 7.12 & 310 \\
\hline 40 & North Palm Springs, 1986 & 2.97 & 0.986 & 16.0 & 4.66 & 295 & 3.99 & 280 \\
\hline
\end{tabular}


Table 5. Set 3: 72-year return period time histories for IO performance level.

\begin{tabular}{|c|c|c|c|c|c|c|c|c|}
\hline \multirow{2}{*}{ EQ } & \multirow{2}{*}{$\begin{array}{l}\text { Record } \\
\text { Name }\end{array}$} & \multirow{2}{*}{ SF } & \multirow{2}{*}{$\begin{array}{c}\text { PGA } \\
(\mathrm{g})\end{array}$} & \multirow{2}{*}{$\begin{array}{c}\text { Excitation } \\
\text { Time } \\
\text { (sec) }\end{array}$} & \multicolumn{2}{|c|}{ LPF1 } & \multicolumn{2}{|c|}{ LPF2 } \\
\hline & & & & & $\beta$ & TNSP & $\beta$ & TNSP \\
\hline 41 & Coyote Lake, 1979 & 2.28 & 0.589 & 12.0 & 6.68 & 310 & 5.96 & 280 \\
\hline 42 & Coyote Lake, 1979 & 2.28 & 0.333 & 12.0 & 5.88 & 295 & 5.43 & 280 \\
\hline 43 & Imperial Valley, 1979 & 0.4 & 0.143 & 15.0 & 6.56 & 295 & 6.08 & 295 \\
\hline 44 & Imperial Valley, 1979 & 0.4 & 0.112 & 15.0 & 9.03 & 310 & 8.60 & 295 \\
\hline 45 & Kern, 1952 & 2.92 & 0.144 & 30.0 & 6.99 & 295 & 6.38 & 295 \\
\hline 46 & Kern, 1952 & 2.92 & 0.159 & 30.0 & 6.95 & 295 & 6.34 & 295 \\
\hline 47 & Landers, 1992 & 2.63 & 0.337 & 25.0 & 6.28 & 295 & 5.92 & 295 \\
\hline 48 & Landers, 1992 & 2.63 & 0.307 & 25.0 & 9.77 & 310 & 8.57 & 310 \\
\hline 49 & Morgan Hill, 1984 & 2.35 & 0.318 & 20.0 & 5.90 & 295 & 5.45 & 310 \\
\hline 50 & Morgan Hill, 1984 & 2.35 & 0.546 & 20.0 & 6.25 & 295 & 5.75 & 280 \\
\hline 51 & Parkfield, 1966, Cholame & 1.81 & 0.780 & 15.0 & 5.52 & 295 & 5.09 & 280 \\
\hline 52 & Parkfield, 1966, Cholame & 1.81 & 0.631 & 15.0 & 7.63 & 310 & 7.11 & 310 \\
\hline 53 & Parkfield, 1966, Cholame & 2.92 & 0.693 & 15.0 & 5.79 & 280 & 5.16 & 295 \\
\hline 54 & Parkfield, 1966, Cholame & 2.92 & 0.790 & 15.0 & 6.14 & 295 & 5.95 & 295 \\
\hline 55 & North Palm Springs, 1986 & 2.75 & 0.517 & 20.0 & 4.57 & 295 & 3.96 & 280 \\
\hline 56 & North Palm Springs, 1986 & 2.75 & 0.379 & 20.0 & 4.49 & 295 & 4.00 & 295 \\
\hline 57 & San Fernando, 1971 & 1.3 & 0.253 & 20.0 & 7.32 & 295 & 7.04 & 310 \\
\hline 58 & San Fernando, 1971 & 1.3 & 0.231 & 20.0 & 6.07 & 295 & 5.65 & 310 \\
\hline 59 & Whittier, 1987 & 1.27 & 0.269 & 15.0 & 6.69 & 310 & 6.16 & 295 \\
\hline 60 & Whittier, 1987 & 1.27 & 0.167 & 15.0 & 6.90 & 310 & 6.34 & 295 \\
\hline
\end{tabular}

Table 6. Random variables utilized for the serviceability risk evaluation.

\begin{tabular}{ccccc}
\hline $\begin{array}{c}\text { Random } \\
\text { Variable }(\mathbf{R V})\end{array}$ & $\begin{array}{c}\text { Number of } \\
\text { RVs }\end{array}$ & Distribution & Mean Value & COV \\
\hline $\mathrm{E}\left(\mathrm{kN} / \mathrm{m}^{2}\right)$ & 1 & Lognormal & $1.9994 \times 10^{8}$ & 0.06 \\
$\mathrm{~F}_{\mathrm{yc}} *\left(\mathrm{kN} / \mathrm{m}^{2}\right)$ & 1 & Lognormal & $3.4474 \times 10^{5}$ & 0.10 \\
$\mathrm{~F}_{\mathrm{yg}} * *\left(\mathrm{kN} / \mathrm{m}^{2}\right)$ & 1 & Lognormal & $2.4822 \mathrm{X} 10^{5}$ & 0.10 \\
$\mathrm{~A}\left(\mathrm{~m}^{2}\right)$ & 30 & Lognormal & $* * *$ & 0.05 \\
$\mathrm{I}_{\mathrm{x}}\left(\mathrm{m}^{4}\right)$ & 30 & Lognormal & $* * *$ & 0.05 \\
$\mathrm{~W}_{\mathrm{D} 1}(\mathrm{kN} / \mathrm{m})$ & 1 & Normal & 32.9457 & 0.10 \\
$\mathrm{~W}_{\mathrm{D} 2}(\mathrm{kN} / \mathrm{m})$ & 1 & Normal & 32.9457 & 0.10 \\
$\mathrm{~W}_{\mathrm{L} 1}(\mathrm{kN} / \mathrm{m})$ & 1 & Type I & 2.9188 & 0.25 \\
$\mathrm{~W}_{\mathrm{L} 2}(\mathrm{kN} / \mathrm{m})$ & 1 & Type I & 2.9188 & 0.25 \\
$\mathrm{~g}_{\mathrm{e}}$ & 1 & Type I & 1.00 & 0.20 \\
\hline
\end{tabular}

*Yield stress of column sections (SAC/FEMA value)

** Yield stress of girder sections (SAC/FEMA value).

*** Since $\mathrm{A}$ and $\mathrm{I}_{\mathrm{x}}$ are taken as random for each section, the mean values are not reported. However, they can be completely found in steel construction manuals. The w-sections utilized for the analysis are illustrated in Figure 3. 
Table 7. Mean values of reliability index $\bar{\beta}$ for each set of ground motions.

\begin{tabular}{ccccccc}
\hline & \multicolumn{2}{c}{$\begin{array}{c}\text { Set } 1(\mathrm{CP}): \text { 2475-Year } \\
\text { Return Period }\end{array}$} & \multicolumn{2}{c}{$\begin{array}{c}\text { Set 2 (LS): 475-Year } \\
\text { Return Period }\end{array}$} & \multicolumn{2}{c}{$\begin{array}{c}\text { Set 3 (IO): 72-Year } \\
\text { Return Period }\end{array}$} \\
& LPF1 & LPF2 & LPF1 & LPF2 & LPF1 & LPF2 \\
\hline $\bar{\beta}$ & 7.06 & 6.22 & 6.96 & 6.32 & 6.57 & 6.05 \\
$\boldsymbol{p}_{f}$ & $8.326 \times 10^{-13}$ & $2.486 \times 10^{-10}$ & $1.701 \times 10^{-12}$ & $1.308 \times 10^{-10}$ & $2.516 \times 10^{-11}$ & $7.242 \times 10^{-10}$ \\
\hline
\end{tabular}

Table 8. Accuracy verifications: serviceability evaluations using MCS and ISS for EQ 36.

\begin{tabular}{ccccc}
\hline \multirow{2}{*}{ Scheme } & \multicolumn{2}{c}{ MCS } & \multicolumn{2}{c}{ ISS } \\
& LPF1 & LPF2 & LPF1 & LPF2 \\
\hline $\boldsymbol{\beta}$ & 4.42 & 3.83 & 4.34 & 3.80 \\
$\boldsymbol{p}_{\boldsymbol{f}}$ & $4.935 \times 10^{-06}$ & $6.407 \times 10^{-05}$ & $7.124 \times 10^{-06}$ & $7.235 \times 10^{-05}$ \\
TNSP & 600,000 & 600,000 & 310 & 310 \\
\hline
\end{tabular}



A center point
$\odot 2 k$ axial points
$2^{k}$ factorial points

Intermediate iterations

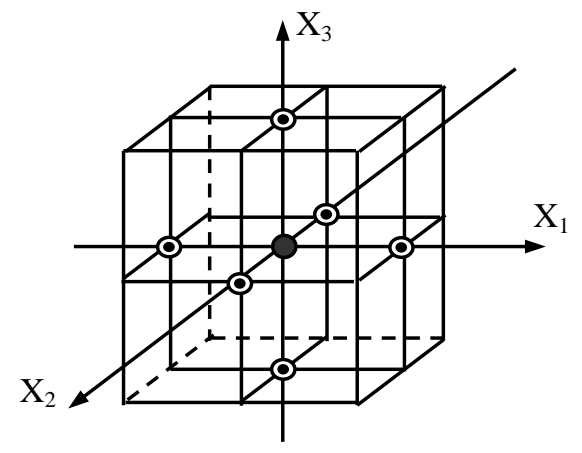

SD and Second Order Polynomial without Cross Terms
Last iteration

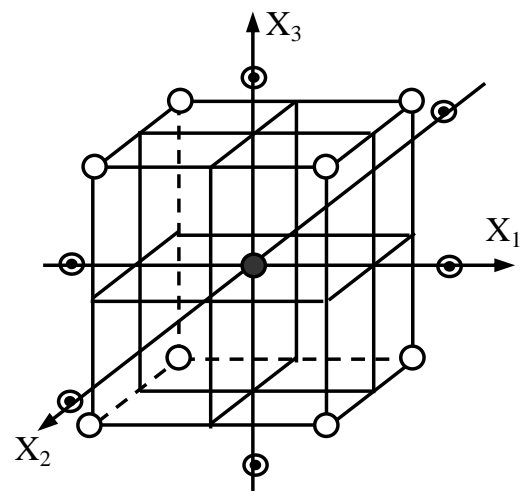

CCD and Second-Order Polynomial with Cross Terms

Figure 1. Improved sampling scheme for three random variables $(k=3): \mathrm{X}_{1}, \mathrm{X}_{2}$, and $\mathrm{X}_{3}$

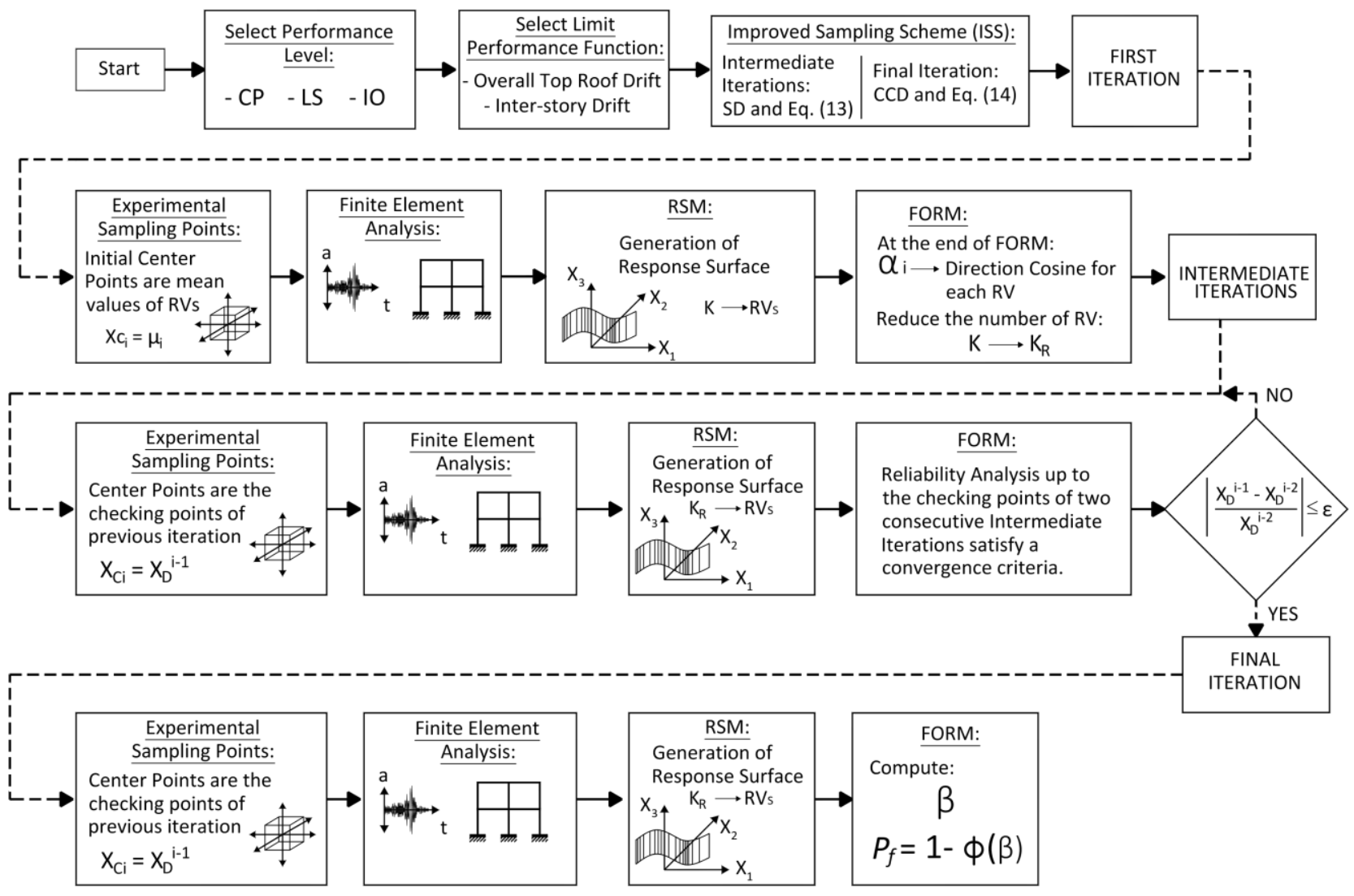

Figure 2. Flowchart of the unified PBSD procedure. 


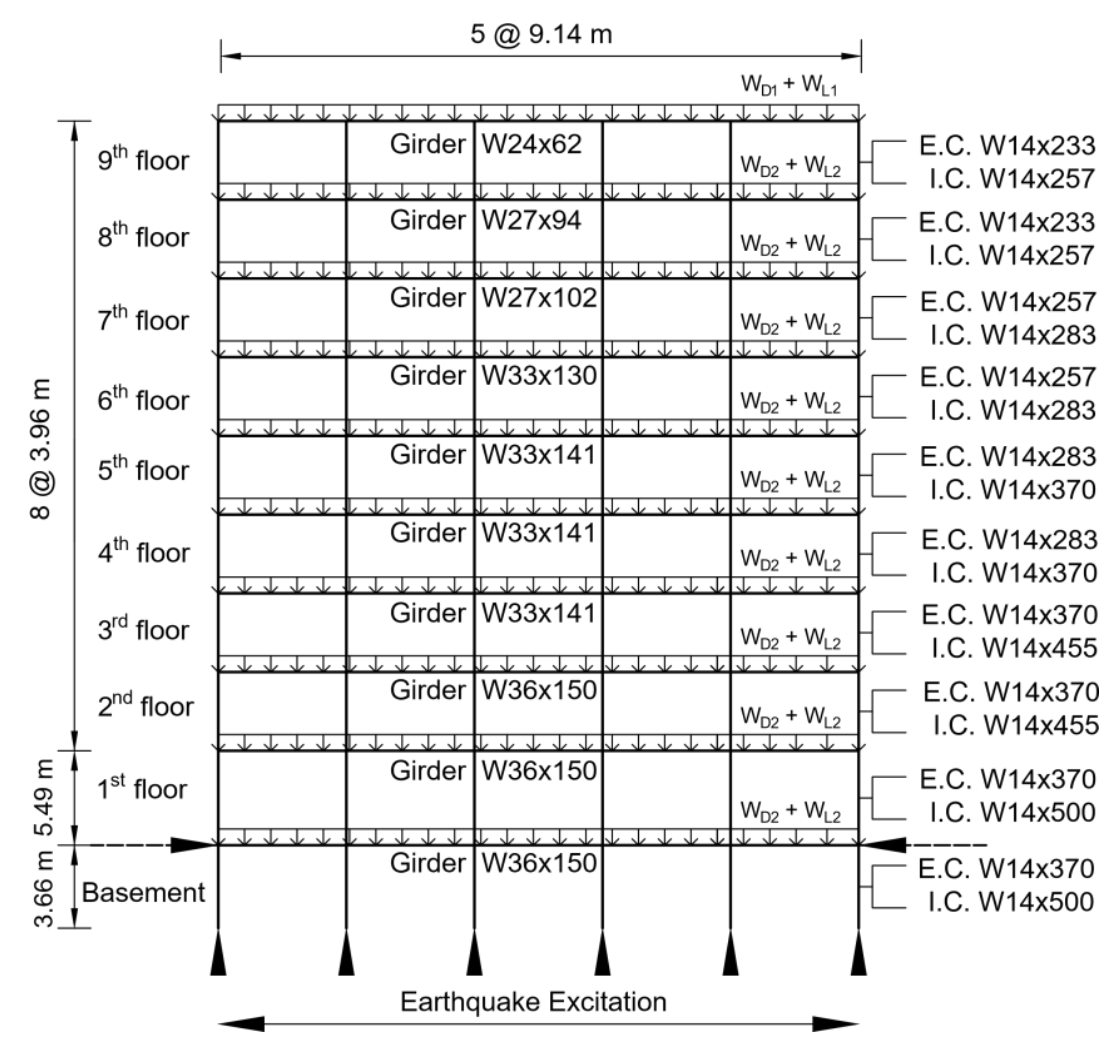

Figure 3. 9-story building (E.C. =Exterior Columns; I.C. =Interior Columns).

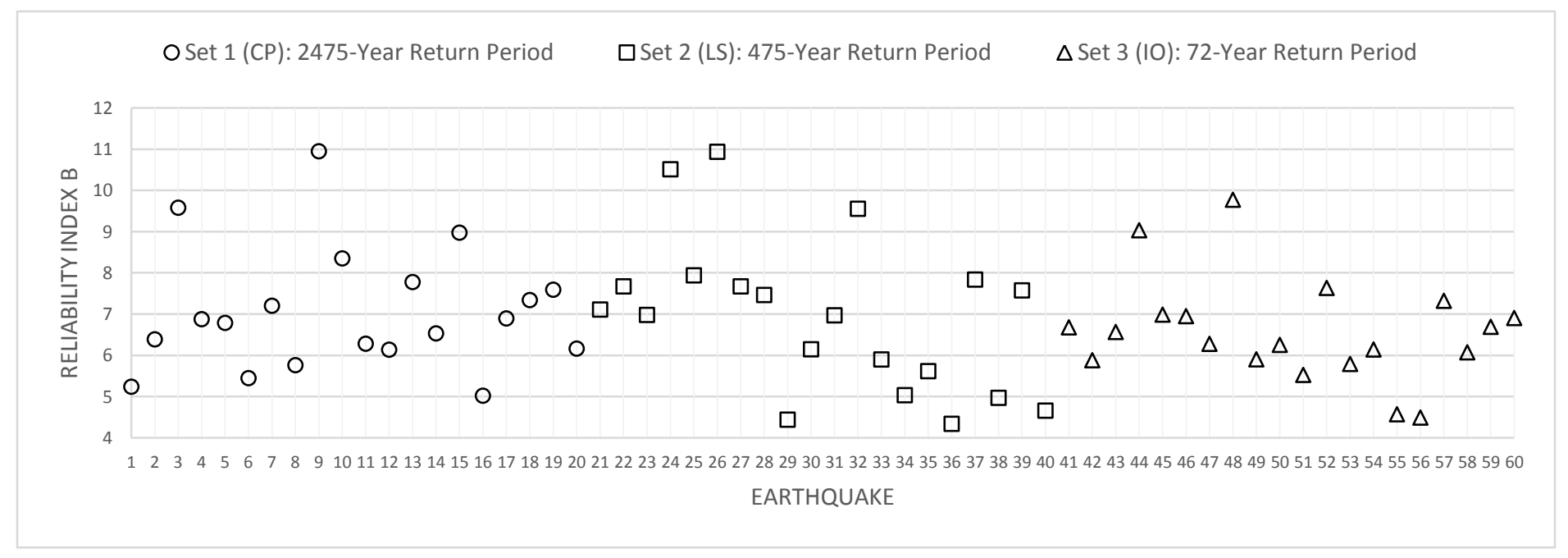

Figure 4. Overall roof drift reliability evaluation (LPF1). 


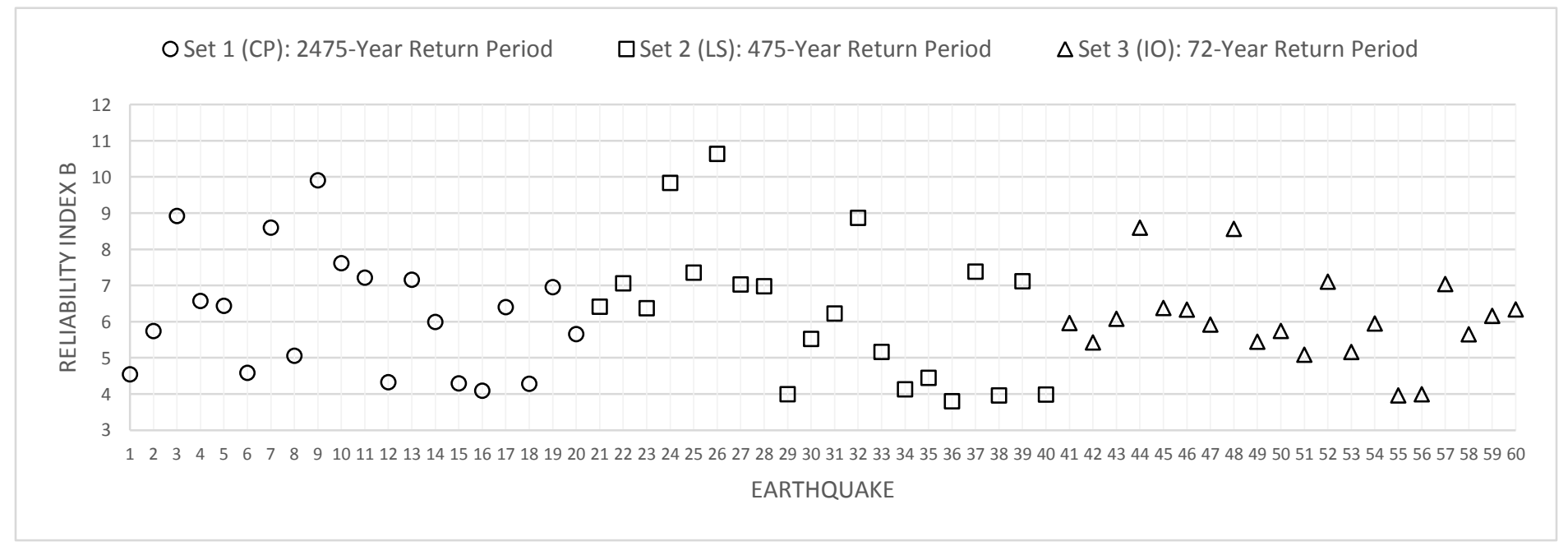

Figure 5. Inter-story ( $4^{\text {th }}$ floor) drift reliability evaluation (LPF2). 